\title{
Integrated Employee Scheduling with Known Employee Demand, Including Breaks, Overtime, and Employee Preferences
}

\author{
Jhunievieve Soriano(iD, Eugene Rex Jalao (iD, Iris Ann Martinez (iD \\ University of the Philippines Diliman (Philippines) \\ jhunievievesoriano@gmail.com,eljalao@up.edu.ph,igmartinez@up.edu.ph
}

Received: February 2020

Accepted: June 2020

\begin{abstract}
:
Purpose: This research paper introduces an integrated employee scheduling problem that considers various real-life problems such as varying employee demand, different employee working conditions, and individual preferences, regarding schedules.

Design/methodology/approach: The proposed model, which is a combination of Analytic Hierarchy Process and Mixed Integer Linear Programming, is used to solve the problem with multi-dimensional objectives period.

Findings: Results show that the proposed model generates optimal and feasible solutions for weekly employee schedules.

Originality/value: Many employee scheduling problems in literature are able to solve the employee scheduling problem to a large extent. However, these studies still do not fully reflect current realistic organizational problems such as varying employee demand per hour interval, different employee working conditions on disjoint shifts and breaks, and individual preferences regarding schedules all at the same time.
\end{abstract}

Keywords: scheduling, AHP, MILP, employee preferences

\section{To cite this article:}

Soriano, J., Jalao, E.R., \& Martinez, I.A. (2020). Integrated employee scheduling with known employee demand, including breaks, overtime, and employee preferences. Journal of Industrial Engineering and Management, 13(3), 451-463. https://doi.org/10.3926/jiem.3126

\section{Introduction}

As one of the most common and difficult organizational problems, the Employee Scheduling Problem (ESP) has been widely studied since it was first formulated by Dantzig (1954) using Integer Linear Programming (ILP). Employee or personnel scheduling, as defined by Ernst, Jiang, Krishnamoorthy and Sier (2004), is the process of constructing work timetables for the staff, assigning qualified workers to meet employee demand for the task, and satisfying employees' working condition and individual preferences. As the number of employees and company size increases, the complexity and challenge to schedule all employees while meeting certain rules, regulations, and worker preferences also increase.

In a review of over 300 related literature on employee scheduling by Van den Bergh, Beliën, De Bruecker, Demeulemeester and De Boeck (2013), the authors have noted that most literature in the ESP domain often 
oversimplify real-life conditions. This results to considerable inaccuracy in the model. Van den Bergh et al. (2013) thus proposed to simultaneously integrate as many aspects as possible (especially controllable variables) to the model. The same paper also enumerated several components of an ESP, as proposed to be integrated into the model. The authors find that the most basic components that appear in real life situations are (i) having employee demand, (ii) a flexible break placement, (iii) employees performing overtime work, and (iv) considering employee preferences such as rest day and vacation leave. An ESP having all of these components will be called Integrated Employee Scheduling Problem (IESP) from hereon.

According to Kletzander, Mischek, Musliu, Post and Winter (2017), the General ESP consists of (i) tasks that need to be done where employee demand arises, (ii) shifts which consist of a group of tasks, and (iii) a set of employees who are assigned to the shifts.

The first component is employee demand, defined by Ernst et al. (2004) as the number of employees needed at different time periods. In a case study done by Kabak, Ülengin, Aktaş, Önsel and Topcu (2008), employee demand for the whole week from 10:00 AM to 21:00 PM varies throughout the day. Furthermore, demand is higher during some days of the week (e.g. weekends). Assuming that there are a constant number of employees available throughout the day, an over-coverage (or under-coverage or shortage) occurs when there are more (or less) employees than demand. Both should be avoided since these leads to additional labor costs and lower service quality, respectively.

The second is shift, consisting of shift type, that depends on the organization. In establishments that do not operate 24 hours in a day (e.g. malls), there are usually only two (2) shift types - opening and closing; while in those that do (e.g. call centers), there are usually multiple shifts - morning, evening, and night. Shifts usually have a length of 9 hours for full-time employees (8 working hours and a 1-hour meal break). Due to the varying employee demands, management often allows flexible breaks placements that are within a time window.

The third component is the set of employees who are heterogeneous in nature, having their own appointment paper or contract. In these documents, the general tasks of the employees are detailed - their working shift, benefits, and working conditions such as hours of work and rest day (RD). Leave benefits like sick leave (SL), vacation leave $(\mathrm{VL})$, and other leaves are very common in many organizations. Some are mandated by the government, but only the Vacation Leave (VL) is planned by the employee and controllable by the management.

Both hours of work and Rest Day (RD), as well as VL, affect employee satisfaction. According to Yee, Yeung and Cheng (2008), it is vital to ensure that employees are satisfied since happy and satisfied employees lead to high service quality and customer satisfaction, which eventually leads to higher profits.

Many past papers concluded that the ESP is typically highly constrained, and it would be difficult to satisfy all restrictions. That is why many opt to categorize the constraints into hard and soft constraints. Hard constraints are the ones that need to be satisfied for a solution to be feasible while soft constraints allow violations that penalize the objective function. Minimizing penalty functions (e.g. unsatisfied preferences of employees) are widely used in the hospital setting since there is usually a high turnover ratio for nurses. Topaloglu (2006) and Huang, Hsieh and Hsia (2016) are some examples of nurse rostering problems that minimized penalty functions. Although this is normal in the hospital setting, it is not yet used in an IESP which considers not just employee preferences, but also overtime, over- and under-coverage from employee demand, and working conditions.

Given this premise, there is a need to solve the Integrated Employee Scheduling Problem (IESP) that reflects current real-world settings which would minimize the total penalty functions of over/under-coverage from employee demand, overtime, and unsatisfied employee preferences simultaneously.

The rest of the paper is organized as follows: section 2 indicates the related literature, gap analysis and solution methodology to be used, section 3 describes the problem and formulation of the proposed model, section 4 shows the validation of the model, and section 5 reveals the sensitivity analysis on the preferences. The last section draws the conclusion and suggested further research. 


\section{Review of Related Literature}

There are many factors that can be highlighted in the Employee Scheduling Problem. For this research paper, most of the literature reviewed considered employee demand in their model. Indeed, employee demand is the most basic and commonly included component in an ESP.

Varying employee demands throughout the day, as well as, constraints such as employees working for consecutive hours in a day expectedly result to over- and under-coverage at different times within the day. However, these can be minimized as in Jones and Nolde (2013) and Dahmen and Rekik (2015). For Dahmen and Rekik (2015), ensuring personnel demand is met was more important than having more staff than needed so the authors put a higher cost on under-coverage while also allowing flexible break placement. Soukour, Devendeville, Lucet and Moukrim (2013), Kuo, Leung and Yano (2014), and Ingels and Maenhout (2017), on the other hand, only took account under-coverage in their models. This is similar with Bürgy, Michon-Lacaze and Desaulniers (2019) that penalizes under-coverage in the problem of employee scheduling that is particularly characterized by demand that has perturbations. While none of the related literature considered to minimize over-coverage only in their objective function, the rest have made it a hard constraint to meet the exact employee demand so that the result will have neither over- or under-coverage of the demand.

Some research papers that deal with solving personnel scheduling look for a schedule that minimizes total labor cost, such as in Bard and Binici (2003) and Alfares (2007). Though sometimes overtime is unavoidable, only Soukour et al. (2013) tried to minimize overtime cost along with undertime, under-coverage, and employee dissatisfaction costs. Valcour (2007) concluded that overworking employees will give them less work-life balance which will likely lead to low satisfaction and high employee turnover rate. Out of the closest related literature, Jones and Nolde (2013) and Bard and Binici (2003) considered an upper bound on the number of days per week an employee should work.

Accordingly, in some service-oriented organizations, entry-level employees are given one (1) or two (2) RDs per week and the employees are allowed to select their preferred RD. Though it is important to give employees some level of job control and increase satisfaction (Wong \& Ko, 2009), it is often neglected in many literatures. Non-consideration of RD preferences results to unfulfilled RDs, particularly when more employees are needed on some days. In addition to RDs, there are also vacation leaves (VLs) per year that employees may request for. It is important to grant requests for a vacation to increase employee satisfaction and quality of life (Gilbert \& Abdullah, 2004). Employees typically request for time-off one (1) to two (2) weeks prior to their desired VL. Although VL is a benefit that most employees have, request for vacation is hardly included in personnel scheduling. From the managerial perspective, it would be useful to have these included in the optimization model to account for employees unavailable for assignment on certain days.

Only in a few studies is the RD preference given importance. These few studies include Huang et al. (2016) that incorporate nurses' preferences on their RDs. Another study is that of Ang, Razali, Asyikin and Kek (2019) that proposes an optimized schedule for security staff that maximizes the satisfaction of the security staff by allowing them to choose their preferred shift and RD, while taking into consideration the organization's (in this study's case, the organization is a university) rules. However, this study has the sole objective of maximizing employee satisfaction. Over/under-coverage is not explicitly stated in the objective.

The objective of maximizing employee satisfaction has also been addressed by some studies, such as Tanazaki, Shimmura, T., \& Fujii (2017) that tackles employee satisfaction by balancing it with customer satisfaction and management satisfaction. In brief, this study's approach to solving the problem of employee scheduling is to assign low-value work to robots and high-value work to employees. This approach is not the same as the approach of this study.

Other characteristics that this study will not consider are scheduling for multiple tasks and multi-skilled employees across different locations as done by Kuo et al. (2014), or same location, multi-rank \& multi-skilled worker as studied by Shuib and Kamarudin (2019). This study will also not consider approaches such as job rotation as contributed by Rerkjirattikal and Olapiriyakul (2019) that looks at job satisfaction related to overtime assignments in a harsh industrial environment, not considering preferred RD. Similar to this study on 
job satisfaction related to overtime, by Yang, Tang and Zhao (2017) that aimed to investigate the employees' job satisfaction on overtime given uncertain demand and operations costs. Furthermore, this study will not consider multiple opportunities for prescheduling overtime prior to the start of the shift as done by Campbell (2017).

Thus, with the aforementioned, the contribution of this research is to bring to the forefront the importance of employee satisfaction, particularly about their preferred RD, which has not been given much attention hitherto, in the same level as previously focused on objectives of minimizing under/over-coverage and overtime.

The IESP is a new variation in the ESP domain that has not yet been solved. For practicality, the MILP can be a starting model that may be extended to more complex IESPs. The proposed solution methodology begins by using AHP to obtain the weights and then plugging those as the objective function coefficients to the MILP model to solve the problem.

\section{Problem Description and Model Formulation}

In this section, the problem description, notations, and mathematical formulation is introduced. The model incorporates the weekly schedules of all employees, their break time, work conditions, and preferences that satisfies all hard and soft constraints at a predefined set.

\subsection{Problem Description}

- One (1) week planning horizon

- 1 -hour time intervals

- Fixed break window per shift type

- Employees are heterogeneous with different preferences

- Work conditions are known

- Contracted number of working hours per day

- Contracted number of working days per week

- Pre-specified shift type

- Employee demand at time period $t$ is deterministically known

- Rest day (RD) and vacation leave (VL) day do not fall on the same day

- Only one (1) VL request is allowed per week

- Fixed maximum overtime/shift/employee

- All employees work full-time with 1-hour break

- No hiring and firing of employees within the planning horizon

- No sudden resignation or sick leave within the planning horizon

\subsection{Notations}

The indices, parameters, decision variables, and dependent variables and their descriptions that will be used to model the Integrated Employee Scheduling Problem (IESP) are listed in Tables 1 to 4, respectively.

\begin{tabular}{|c|l|}
\hline Indices & \multicolumn{1}{|c|}{ Description } \\
\hline$E$ & Set of employees $e \in E(e=1,2, \ldots, n)$ \\
\hline$J$ & Set of shift-types $j \in J(j=0,1,2, \ldots, m) \rightarrow(1=$ morning, $2=\operatorname{mid}, \ldots, m)$ \\
\hline$D$ & Set of days $d \in D(d=1,2, \ldots, 7)$ \\
\hline$T$ & Set of time periods $t \in T(t=1,2, \ldots, 24)$ \\
\hline
\end{tabular}

Table 1. Indices 


\begin{tabular}{|c|c|}
\hline Parameters & Description \\
\hline$H$ & $\begin{array}{l}\text { Number of contracted working hours per shift for employees (regular working hours) excluding break } \\
\text { time }\end{array}$ \\
\hline $\operatorname{Min}$ & Minimum number of contracted working days per week \\
\hline $\operatorname{Max}$ & Maximum number of contracted working days per week \\
\hline$r d_{e}$ & Employee $e$ 's preferred rest day $(r d) d$ \\
\hline$v l_{e}$ & Employee $e$ 's preferred vacation leave $(v l)$ day $d$ if any \\
\hline$J_{e}$ & Pre-determined shift of employee $e$ \\
\hline$s t_{j}$ & Start time for shift type $j$ \\
\hline eet & Earliest end time for shift type $j$ \\
\hline let & Latest end time for shift type $j$ \\
\hline$e b_{j}$ & Earliest break time for shift type $j$ \\
\hline$l b_{j}$ & Latest break time for shift type $j$ \\
\hline OT & Maximum allowable overtime work per shift \\
\hline $\mathrm{R}_{d t}$ & Number of employees needed at day $d$ at time period $t$ (employee demand) \\
\hline$W_{\alpha}$ & Penalty weight for over-coverage \\
\hline$W_{\beta}$ & Penalty weight for under-coverage \\
\hline$W_{\pi}$ & Penalty weight for overtime work \\
\hline$W_{\omega}$ & Penalty weight for not granting an employee's request for $R D$ \\
\hline$W_{\lambda}$ & Penalty weight for not granting an employee's request for $V L$ \\
\hline
\end{tabular}

Table 2. Parameters

\begin{tabular}{|l|l|}
\hline $\begin{array}{l}\text { Decision } \\
\text { variables }\end{array}$ & Description \\
\hline$x_{\text {elj }}$ & 1 if employee $e$ is assigned to work on day $d$ at shift $j ; 0$ otherwise \\
\hline$y_{\text {eljit }}$ & 1 if employee $e$ is assigned to work on day $d$ at shift $j$ at time period $t ; 0$ otherwise \\
\hline$b r_{e l j t}$ & 1 if employee $e$ working on day $d$ assigned to shift $j$ is given a 1 -hour break at time period $t ; 0$ otherwise \\
\hline
\end{tabular}

Table 3. Decision Variables

\begin{tabular}{|l|l|}
\hline $\begin{array}{l}\text { Dependent } \\
\text { variables }\end{array}$ & Description \\
\hline$\alpha_{d t}$ & Number of employees over-covered at day $d$ at time period $t$ \\
\hline$\beta_{d t}$ & Number of employees under-covered at day $d$ at time period $t$ \\
\hline$\pi_{d t}$ & Total \# of overtime hours worked by employee $e$ at day $d$ at shift $j$ \\
\hline
\end{tabular}

Table 4. Dependent Variables

\subsection{Formulation}

The IESP will be solved by minimizing the total of objective functions subject to the following constraints (C\#1 to C\#15). The first and second terms in the objective function are the over- and under-coverage from the employee demand multiplied to their corresponding penalty weights. The third term is the total overtime work performed multiplied to the overtime penalty weight. While the fourth and fifth terms are the total unsatisfied (or not granted) preferences in rest day (RD) and vacation leave (VL) requests multiplied to their corresponding penalty weights. 


$$
\begin{array}{r}
\operatorname{Min}_{z}=w_{\alpha}\left(\sum_{t \in T} \sum_{d \in D} \alpha_{d t}\right)+w_{\beta}\left(\sum_{t \in T} \sum_{d \in D} \beta_{d t}\right)+w_{\pi}\left(\sum_{e \in E} \sum_{d \in D} \sum_{j \in J_{e}} \pi_{e d j}\right) \\
+w_{\omega}\left(\sum_{e \in E} \sum_{d \in r d_{e}} \sum_{j \in J_{e}} x_{e d j}\right)+w_{\lambda}\left(\sum \sum_{e \in E} \sum_{d \in v l_{e}} x_{j \in J_{e}}\right)
\end{array}
$$

\section{Subject to:}

(C\#1) Total assigned workdays per week should be at least the minimum number of contracted workdays.

$$
\sum_{d \in D} \sum_{j \in J_{e}} x_{e d j} \geq \operatorname{Min} \forall e \in E
$$

(C\#2) Total assigned workdays per week should not exceed the maximum number of contracted workdays.

$$
\sum_{d \in D} \sum_{j \in J_{e}} x_{e d j} \leq \operatorname{Max} \forall e \in E
$$

(C\#3) Employees who did not request for vacation leave (VL) should work exactly the maximum number of contracted workdays per week.

$$
\sum_{d \in D} \sum_{j \in J_{e}} x_{e d j}=\operatorname{Max}-v l_{e} \forall e \in E, v l_{e}=0
$$

(C\#4) 1-hour meal break should be assigned to employees within a time window $\left[e b_{j}, l b_{j}\right]$ for employee $e$ assigned to work on day $d$ at shift $j\left(x_{e l j}=1\right)$.

$$
\sum_{t \in\left[e b_{j}, l b_{j}\right]} b r_{e d j t}=x_{e d j} \forall e \in E, d \in D, j \in J_{e}
$$

(C\#5) If employee $e$ is assigned to work on day $d$ at shift $j\left(\chi_{e d j}=1\right)$, he is also assigned to perform work within his shift $t \in\left[s t_{j}\right.$, eet $]$ with a 1 -hour break during his regular working hours.

$$
\sum_{t \in\left[s t_{j}, e e t_{j}\right]}\left(y_{e d j t}-b r_{e d j t}\right)=(H)\left(x_{e d j}\right) \forall e \in E, d \in D, j \in J_{e}
$$

(C\#6) The total overtime of employee $e$ at day $d$ who is assigned to shift $j$ is called $\pi_{e l j}$.

$$
\sum_{t \in\left[e e t_{j}+1, \text { let }_{j}\right]} y_{\text {edjt }}=\pi_{e d j} \forall e \in E, d \in D, j \in J_{e}
$$

(C\#7) Total overtime $\pi_{e l j}$ per day $d$ at shift $j$ per employee $e$ should not exceed allowable overtime (OT) per day if he is assigned to work on day $d\left(\chi_{e d j}=1\right)$.

$$
\pi_{e d j} \leq O T\left(x_{e d j}\right) \forall e \in E, d \in D, j \in J_{e}
$$

(C\#8) If an employee is assigned to work during overtime (OT) hours $\left(t \in\left[e t_{j}+1\right.\right.$, let $]$ ), he should also be assigned to the preceding time period within the OT hours to ensure continuous assignment of work during overtime.

$$
y_{e d j(t-1)} \geq y_{e d j t} \forall e \in E, d \in D, j \in J_{e}, t \in\left[\text { eet }+2 \text {, let } t_{j}\right]
$$

(C\#9) Total available employees which is the total employees working less employees who are on break $\left(\sum_{e \in E} \sum_{j \in J e} y_{e d j t}-b r_{e d j i t}\right)$ should meet employee demand at day $d$ at each time period $t$, allowing for over-coverage $\left(\alpha_{d t}\right)$ and under-coverage $\left(\beta_{d t}\right)$. 


$$
\left(\sum_{e \in E} \sum_{j \in J_{e}} y_{e d j t}-b r_{e d j t}\right)-\alpha_{d t}+\beta_{d t}=R_{d t} \forall d \in D, t \in T
$$

(C\#10) Employee $e$ at days $d$ should not be assigned to shifts $j$ and time periods $t$ outside of his regular working hours and overtime period.

$$
y_{\text {edjt }}=0 \forall e \in E, d \in D, j \in J_{e}, t \notin\left[s t_{j}, \text { let }_{j}\right]
$$

(C\#11) Employee $e$ at days $d$ should not be assigned to days $d$ and time periods $t$ outside his assigned shift $j$.

$$
y_{\text {edjt }}=0 \forall e \in E, d \in D, j \notin J_{e}, t \in T
$$

(C\#12) Employee $e$ at days $d$ should not be assigned to a break outside of his break window time periods $t$ for his assigned shift $j$.

$$
b r_{e d j t}=0 \forall e \in E, d \in D, j \in J_{e}, t \notin\left[e b_{j}, l b_{j}\right]
$$

(C\#13) Employee $e$ at days $d$ should not be assigned to a break outside his assigned shift $j$ for all time periods $t$.

$$
b r_{e d j t}=0 \forall e \in E, d \in D, j \notin J_{e}, t \in T
$$

(C\#14) $x_{\text {elj; } j} y_{\text {eljit }}$ and $b r_{\text {eljit }}$ are binary variables.

$$
x_{e d j}, y_{\text {edjt }}, b r_{\text {edjt }} \in\{0,1\} \forall e \in E, d \in D, j \in J_{e}, t \in T
$$

$(\mathrm{C} \# 15)$ Over-coverage $\left(\alpha_{d t}\right)$ and under-coverage $\left(\beta_{d t}\right)$ are non-negative variables.

$$
\alpha_{d t}, \beta_{d t} \geq 0 \forall d \in D, t \in T
$$

\section{Validation of the Model}

To validate the proposed model and solution method, published data from Alfares (2007) is used. The solution of Alfares (2007) showed a set of employees and their tour assignments that consist of shift types with defined start and end time, break time, and pre-specified rest days. For simplicity, instead of using, time periods will be used hours (e.g. time period $1=00: 00 \mathrm{AM}$ to 01:00 AM, time period $2=01: 00 \mathrm{AM}$ to 02:00 AM, etc.). The problem summary, as well as changes and additional assumptions, are listed in Table 5, while the actual data on demand was retained as is in Alfares (2007). The readers are referred to Alfares (2007) for a reference. A visual representation of the new shifts is depicted on Figure 1.

\begin{tabular}{|r|r|c|c|c|c|c|c|c|c|c|c|c|c|c|c|c|c|c|c|c|c|c|c|c|}
\hline \multirow{2}{*}{ Shift } & \multicolumn{10}{|c|}{ Time Period } & \# of \\
& 1 & 2 & 3 & 4 & 5 & 6 & 7 & 8 & 9 & 10 & 11 & 12 & 13 & 14 & 15 & 16 & 17 & 18 & 19 & 20 & 21 & 22 & 23 & 24 \\
Employees \\
\hline 1
\end{tabular}

Figure 1. Visual representation of the new shifts.

Black means the regular nine (9) working time periods (e.g. time period 7 to 15 for shift 1), yellow is the break window, and gray is the possible overtime work period (e.g. time period 16 to 19 for shift 1). 


\begin{tabular}{|c|c|c|}
\hline Description & Alfares (2007) & Proposed Model \\
\hline Employee demand & \multicolumn{2}{|c|}{ Known, hourly (24 hours), one (1) week } \\
\hline Day employees and contractors & \multicolumn{2}{|r|}{24 employees } \\
\hline \multirow{3}{*}{ Shift } & 06:00-15:00 & 06:00-15:00 (Shift 1) \\
\hline & 10:00-19:00 & 10:00-19:00 (Shift 2) \\
\hline & $15: 00-24: 00$ & 15:00-24:00 (Shift 3) \\
\hline \multirow{3}{*}{ Break } & $\begin{array}{l}\text { Shift 1: 11:00-12:00, } \\
\text { 12:00-13:00 }\end{array}$ & \multirow{3}{*}{$\begin{array}{l}\text { 1-hour break for all within break window } \\
\text { Shift } j=[\text { start time }+3 \text {, start time }+5]\end{array}$} \\
\hline & Shift 3: 13:00-14:00, 19:00-20:00 & \\
\hline & Shift 4: 20:00-21:00 & \\
\hline Rest day & Pre-specified and fixed & $\begin{array}{l}\text { Pre-specified rest days in Alfares (2007) } \\
\text { are assumed to be the preferred }\end{array}$ \\
\hline Shift employees & \multicolumn{2}{|c|}{20 employees with 3 different shifts } \\
\hline \multirow{3}{*}{ Shift } & 07:00-15:00 & 06:00-15:00 (Shift 1) \\
\hline & 15:00-23:00 & 15:00-24:00 (Shift 3) \\
\hline & 23:00-07:00 & 23:00-08:00 (Shift 4) \\
\hline Break & None & 1-hour break for all \\
\hline Rest day & Varying & Random and consecutive: unif $\{1,7\}$ \\
\hline Vacation Leave & $\mathrm{N} / \mathrm{A}$ & Random and adjacent to RD: unif $\{0,1\} ; \pm 1$ of rest day \\
\hline Overtime & $\mathrm{N} / \mathrm{A}$ & Maximum of 4 hours per day \\
\hline Min and Max Workdays & $\mathrm{N} / \mathrm{A}$ & 4 - 5 days per week \\
\hline
\end{tabular}

Table 5. Problem Summary of Alfares (2007) and the Proposed Model.

Rest days of the shift employees are varying and not given in Alfares (2007) so the rest days in the proposed model will assume random consecutive days since according to Nanda and Browne (1992), nonconsecutive days off are less desirable for employees. Vacation leave is also not included in the data set. It will be randomized using a discrete uniform distribution between 0 and 1 ( $50 \%$ probability for each). A value of 0 means the employee did not request for a vacation leave, while a value of 1 means the employee requested for a vacation within the planning horizon. If an employee requests for vacation, it is assumed to be adjacent to the rest day for a total of three (3) consecutive off days (Nanda and Browne, 1992). Lastly, the maximum overtime is assumed to be $50 \%$ of the working hours per shift which is four (4) hours for all employees, while the minimum and maximum working days per week for all employees are four (4) and five (5) days because there are two (2) rest days (maximum of 5 working days) and one (1) allowable vacation leave request (minimum of 4 working days).

The total number of employees is 44 and there are two (2) days of rest day (RD) request for each employee for a total of 88 rest day requests. After generating randomly who among the employees will request for vacation leave (VL), a total of 18 VL requests came up. In addition, the probability distribution and assumptions on RDs for the shift employees and VL request for all employees are summarized in Table 6.

At this point, it is important to note that in this IESP, the weights calculated are based on the preferences of the shift manager/supervisor on how they would manage their staff's schedule. As seen above, most of the validation, particularly for the job satisfaction in terms of meeting the preferred rest days, was done by simulation. In order to augment this, this study interviewed one real respondent and collected the respondent's set of preferences when scheduling staff. The respondent works at a Restaurant as a Shift Manager who delegates tasks to staff and manage their shifts (see below for a detailed professional profile). In a different industry or organization, the personnel who manages the staff schedules may have a different set of preferences that is consistent (Consistency Ratio < 0.10) which would result to a different optimal solution. 


\begin{tabular}{|l|c|l|}
\hline \multicolumn{1}{|c|}{ Work condition } & Distribution & \multicolumn{1}{c|}{ Description } \\
\hline Rest day \#1 (RD\#1) & unif $\{1,7\}$ & Discrete uniform distribution \\
\hline Rest day \#2 (RD\#2) & N/A & $\begin{array}{l}+1 \text { of RD\#1 for RD\#1 }=1, \ldots, 6 \\
-1 \text { of RD\#2 for RD\#1 } 7\end{array}$ \\
\hline Requesting for vacation leave (VL) or not & unif $\{0,1\}$ & $\begin{array}{l}0=\text { employee did not request for VL }(50 \%) \\
1=\text { employee is requesting for VL }(50 \%)\end{array}$ \\
\hline VL day (if requested) & N/A & $\begin{array}{l}+1 \text { of RD\#2 for RD\#1 }=1, \ldots, 6 \\
-1 \text { of RD\#1 for RD\#2 }=7\end{array}$ \\
\hline
\end{tabular}

Table 6. Probability distribution and assumptions for rest day and vacation leave

\begin{tabular}{|l|c|c|c|c|c|}
\hline \multicolumn{1}{|c|}{ Objective } & (1) & (2) & (3) & (4) & (5) \\
\hline (1) Over-coverage & 1 & $1 / 9$ & $1 / 4$ & $1 / 8$ & $1 / 7$ \\
\hline (2) Under-coverage & 9 & 1 & 5 & 2 & 3 \\
\hline (3) Overtime & 4 & $1 / 5$ & 1 & $1 / 3$ & $1 / 2$ \\
\hline (4) Preferred RD & 8 & $1 / 2$ & 3 & 1 & 2 \\
\hline (5) Preferred VL & 7 & $1 / 3$ & 2 & $1 / 2$ & 1 \\
\hline
\end{tabular}

Table 7. AHP pairwise comparison matrix

\section{Respondent's professional profile}

Industry: Food and Beverage (Restaurant)

Company: Confidential

Respondent: Confidential

Position: Shift Manager

Years in Company: 2 years

Prior similar experience: 4 years

Job role:

1) Delegating tasks to restaurant staff and supervising their performance.

2) Planning for each shift and monitoring performance during the shift.

3) Maintaining a fully stocked inventory and ordering food supplies, as needed.

4) Entering and checking of daily time records and sending to employee cooperative/agency.

5) Managing dining reservations.

6) Administrative duties.

In getting the AHP matrix, the Shift Manager was interviewed and asked to fill the pairwise comparison matrix in Table 7 on the consideration of every objective in scheduling employees. The AHP matrix is then normalized as shows in tale 10. Finally, the weights of the objectives, as well as the rankings summarized in Table 9 were calculated using MS Excel and then exported to LINGO to solve the IESP.

\begin{tabular}{|l|l|l|l|l|l|}
\hline \multicolumn{1}{|c|}{ Objective } & (1) & (2) & (3) & (4) & (5) \\
\hline (1) Over-coverage & 0.0345 & 0.0518 & 0.0222 & 0.0316 & 0.0215 \\
\hline (2) Under-coverage & 0.3103 & 0.4663 & 0.4444 & 0.5053 & 0.4516 \\
\hline (3) Overtime & 0.1379 & 0.0933 & 0.0889 & 0.0842 & 0.0753 \\
\hline (4) Unsatisfied RD & 0.2759 & 0.2332 & 0.2667 & 0.2526 & 0.3011 \\
\hline (5) Unsatisfied VL & 0.2414 & 0.1554 & 0.1778 & 0.1263 & 0.1505 \\
\hline
\end{tabular}

Table 8. Normalized pairwise comparison matrix 


\begin{tabular}{|l|r|r|}
\hline \multicolumn{1}{|c|}{ Objective } & \multicolumn{1}{c|}{ Weight } & \multicolumn{1}{c|}{ Rank } \\
\hline (1) Over-coverage & 0.0323 & 5 \\
\hline (2) Under-coverage & 0.4356 & 1 \\
\hline (3) Overtime & 0.0959 & 4 \\
\hline (4) Unsatisfied RD & 0.2659 & 2 \\
\hline (5) Unsatisfied VL & 0.1703 & 3 \\
\hline
\end{tabular}

Table 9. Weights of the objectives used and their ranking

To check if the weights of the objectives are consistent (i.e. if criterion $\mathrm{A}$ is more important than $\mathrm{B}$, and $\mathrm{B}$ is more important than C, then A is more important than C), the Consistency Ratio (CR) shall be computed. Saaty (1980) suggested Random Index (RI) values to determine consistency wherein a comparison matrix is deemed consistent if the $\mathrm{CR}<0.10$. It is thus computed as follows, with $n$ being the number of objectives being compared:

$$
C R=\frac{C I}{R I(n)}=\frac{0.0247}{1.12}=0.02205
$$

Since CR $=0.02205<0.10$, it can be said that the comparison is consistent. After plugging the penalty weights of each objective in LINGO, results show a global optimum solution with an objective value of 23.0294. Since there are zero (0) infeasibilities, this mean that no (hard) constraints were violated. In addition to the objective value, the total number of penalties (soft constraints) are summarized in Table 10. It includes deviations from employee demand (over- and under-coverage), a total of 86 hours of overtime work performed by all employees, 22 unsatisfied rest day requests, and five (5) unsatisfied vacation leave requests within a week for 44 employees.

\begin{tabular}{|l|c|}
\hline \multicolumn{1}{|c|}{ Objective } & Result \\
\hline Over-Coverage & 250 hours \\
\hline Under-Coverage & 0 hours \\
\hline Overtime & 86 hours \\
\hline Unsatisfied Rest Day & 22 out of 88 requests \\
\hline Unsatisfied Vacation Leave & 5 out of 18 requests \\
\hline
\end{tabular}

Table 10. Summary of results from Proposed Model

\section{Sensitivity Analysis}

To evaluate the robustness of the results, a sensitivity analysis of the preferences was made due to its innate variability. To do this, let every comparison in the AHP matrix vary randomly by \pm 1 as suggested by Emblemsvåg and Tonning (2003). That is, if a score of 5 is given between a comparison, the score of the same comparison can vary between 4 and 6 . A simulation was run with 200 data points and five (5) replications which showed an average deviation of $3.27 \%$ from the original weights.

Including all replications and data points, results in Table 11 show that over-coverage (rank 5) is always at the same rank. Under-coverage consistently had the highest weight (rank 1), 99.3\% of the time; overtime (rank 4) stayed the same $99.9 \%$ of the 200 data points and five (5) replications; while unsatisfied rest days (rank 2) and vacation leave (rank 3 ) had the $2^{\text {nd }}$ and $3^{\text {rd }}$ highest weights $96.4 \%$ and $96.7 \%$ of the time among the objectives, respectively.

Several instances wherein the rankings were changed (e.g. the \% same rank is $<100 \%$ as described in Table 12) were check for any changes in the objective value and whether a feasible solution will still be found. Results show that the penalty weights of an instance of each of the five (5) cases were plugged into the objective function. After running the model using the simulated penalty weights, a global optimum solution was found for all cases (Table 13).It is clear that even if the preferences vary randomly by \pm 1 and rankings changed in some instances, there is only minimal change in the solutions generated. Therefore, it can be said that the preferences are robust. 


\begin{tabular}{|c|l|r|}
\hline Original Rank & \multicolumn{1}{|c|}{ Objective } & \multicolumn{1}{c|}{$\%$ same rank } \\
\hline 5 & Over-Coverage & $100.0 \%$ \\
\hline 1 & Under-Coverage & $98.9 \%$ \\
\hline 4 & Overtime (OT) & $99.9 \%$ \\
\hline 2 & Unsatisfied Rest Day (RD) & $96.2 \%$ \\
\hline 3 & Unsatisfied Vacation Leave (VL) & $97.3 \%$ \\
\hline
\end{tabular}

Table 11. Percentage of the time the objectives remain their original rank

\begin{tabular}{|c|l|r|}
\hline Case & \multicolumn{1}{|c|}{ Description } & Number of instances \\
\hline 1 & Under-C (rank1) and RD (rank 2) switched & 11 \\
\hline 2 & Under-C (rank 1) and RD (rank 2) tied at rank 1 & 4 \\
\hline 3 & RD (rank 2) and VL (rank 3) switched & 23 \\
\hline 4 & RC (rank 2) and VL (rank 3) tied at rank 2 & 3 \\
\hline 5 & VL (rank 3) and OT (rank 4) switched & 1 \\
\hline & Total & 42 \\
\hline
\end{tabular}

Table 12. Cases and number of instances of changed rankings

\begin{tabular}{|c|r|r|r|r|r|r|r|}
\hline Case & Obj. value & CPU time (s) & Over-C & Under-C & OT & Uns-RD & Uns-VL \\
\hline 1 & 25.5655 & 2.99 & 252 & 2 & 78 & 22 & 5 \\
\hline 2 & 24.9409 & 2.91 & 250 & 0 & 86 & 22 & 5 \\
\hline 3 & 22.2582 & 5.55 & 260 & 0 & 80 & 28 & 0 \\
\hline 4 & 21.8568 & 11.55 & 254 & 0 & 82 & 27 & 1 \\
\hline 5 & 25.7788 & 9.00 & 256 & 2 & 74 & 23 & 5 \\
\hline
\end{tabular}

Table 13. Results of plugging penalty weights for all five (5) cases

\section{Conclusion and Further Study}

In this research paper, a new integrated employee scheduling problem (IESP) was introduced which reflects current real-world settings. The IESP has basic components that appear in real-life situations such as varying demand, possibility to render overtime, flexible break placement, and employee preference consideration. To solve the IESP, an AHP + MILP model was proposed and tested using published data from Alfares (2007) and produced a global optimum solution. While preferences are subjective and are variable in nature, sensitivity analysis is used to evaluate the robustness of the preferences by allowing the comparisons to vary randomly by \pm 1 . The analysis shows that at least $96.2 \%$ of the time for 200 runs and five (5) replications, the ranking of the objectives stays the same.

The integrated employee scheduling problem (IESP) introduced in this paper is a new problem relevant to current industry standards. Thus, the proposed model in this research paper can be a base model, to which future researchers can add other components.

\section{Declaration of Conflicting Interests}

The authors declared no potential conflicts of interest with respect to the research, authorship, and/or publication of this article.

\section{Funding}

The authors received financial support from the Engineering Research and Development for Technology (ERDT) program of the Department of Science and Technology and the College of Engineering, UP Diliman for the research, authorship, and/or publication of this article 


\section{References}

Alfares, H.K. (2007). Operator staffing and scheduling for an IT-help call centre. European Journal of Industrial Engineering, 1(4), 414-430. https://doi.org/10.1504/EJIE.2007.015389

Ang, S.Y., Razali, M., Asyikin, S.N., \& Kek, S.L. (2019). Optimized preference of security staff scheduling using integer linear programming approach. An International Journal of Advanced Computer Technology, 8(4).

Bard, J.F., \& Binici, C. (2003). Staff scheduling at the United States postal service. Computers \& Operations Research, 30(5), 745-771. https://doi.org/10.1016/S0305-0548(02)00048-5

Bürgy, R., Michon-Lacaze, H., \& Desaulniers, G. (2019). Employee scheduling with short demand perturbations and extensible shifts. Omega, 89, 177-192. https://doi.org/10.1016/j.omega.2018.10.009

Campbell, G.M. (2017). Time-staged overtime staffing for services with updated forecasts and availabilities. Decision Sciences, 48(4), 691-722. https://doi.org/10.1111/deci.12237

Dahmen, S., \& Rekik, M. (2015). Solving multi-activity multi-day shift scheduling problems with a hybrid heuristic. Journal of Scheduling, 18(2), 207-223. https://doi.org/10.1007/s10951-014-0383-z

Dantzig, G.B. (1954). Traffic delays at toll booths. Journal of the Operations Research Society of America, 2(3), $339-341$. https://doi.org/10.1287/opre.2.3.339

Emblemsvåg, J., \& Tonning, L. (2003). Decision support in selecting maintenance organization. Journal of Quality in Maintenance Engineering, 9(1), 11-24. https:/ / doi.org/10.1108/13552510310466765

Ernst, A.T., Jiang, H., Krishnamoorthy, M., \& Sier, D. (2004). Staff scheduling and rostering: A review of applications, methods and models. European Journal of Operational Research, 153(1), 3-27. https://doi.org/10.1016/S0377-2217(03)00095-X

Gilbert, D., \& Abdullah, J. (2004). Holiday taking and the sense of well-being. Annals of Tourism Research, 31(1), 103-121. https://doi.org/10.1016/j.annals.2003.06.001

Huang, Y.C., Hsieh, Y.H., \& Hsia, F.Y. (2016). A study on nurse day-off scheduling under the consideration of binary preference. Journal of Industrial and Production Engineering, 33(6), 363-372. https://doi.org/10.1080/21681015.2015.1095805

Ingels, J., \& Maenhout, B. (2017). Employee substitutability as a tool to improve the robustness in personnel scheduling. OR Spectrum, 39(3), 623-658. https:/ / doi.org/10.1007/s00291-017-0476-0

Jones, C.N., \& Nolde, K. (2013). Demand-driven employee scheduling for the Swiss market.

Kabak, Ö., Ülengin, F., Aktaş, E., Önsel, Ş., \& Topcu, Y.I. (2008). Efficient shift scheduling in the retail sector through two-stage optimization. European Journal of Operational Research, 184(1), 76-90.

https://doi.org/10.1016/j.ejor.2006.10.039

Kletzander, L., Mischek, F., Musliu, N., Post, G., \& Winter, F. (2017). A general modeling format for employee scheduling. Technical Report, DBAI-TR, TU Wien. Available at: http://www. dbai.tuwien.ac.at/proj/arte/ (Accessed: March 2017).

Kuo, Y.H., Leung, J.M., \& Yano, C.A. (2014). Scheduling of Multi-skilled Staff Across Multiple Locations. Production and Operations Management, 23(4), 626-644. https://doi.org/10.1111/poms.12184

Nanda, R., \& Browne, J. (1992). Introduction to employee scheduling. Van Nostrand Reinhold.

Rerkjirattikal, P., \& Olapiriyakul, S. (2019). Overtime Assignment and Job Satisfaction in Noise-Safe Job Rotation Scheduling. In International Symposium on Integrated Uncertainty in Knowledge Modelling and Decision Making (26-37). Cham: Springer. https://doi.org/10.1007/978-3-030-14815-7_3

Saaty, T.L. (1980). The analytical hierarchy process. New York: McGraw-Hill. https://doi.org/10.21236/ADA214804

Shuib, A., \& Kamarudin, F.I. (2019). Solving shift scheduling problem with days-off preference for power station workers using binary integer goal programming model. Annals of Operations Research, 272(1-2), 355-372. https://doi.org/10.1007/s10479-018-2848-5 
Soukour, A.A., Devendeville, L., Lucet, C., \& Moukrim, A. (2013). A memetic algorithm for staff scheduling problem in airport security service. Expert Systems with Applications, 40(18), 7504-7512.

https://doi.org/10.1016/j.eswa.2013.06.073

Tanizaki, T., Shimmura, T., \& Fujii, N. (2017). Shift scheduling to improve customer satisfaction, employee satisfaction and management satisfaction in service workplace where employees and robots collaborate. In International Conference on Serviceology (15-25). Cham: Springer. https://doi.org/10.1007/978-3-319-61240-9_2

Topaloglu, S. (2006). A multi-objective programming model for scheduling emergency medicine residents. Computers \& Industrial Engineering, 51(3), 375-388. https://doi.org/10.1016/j.cie.2006.08.003

Valcour, M. (2007). Work-based resources as moderators of the relationship between work hours and satisfaction with work-family balance. Journal of Applied Psychology, 92(6), 1512. https://doi.org/10.1037/0021-9010.92.6.1512

Van den Bergh, J., Beliën, J., De Bruecker, P., Demeulemeester, E., \& De Boeck, L. (2013). Personnel scheduling: A literature review. European Journal of Operational Research, 226(3), 367-385. https://doi.org/10.1016/j.ejor.2012.11.029

Wong, S.C.K., \& Ko, A. (2009). Exploratory study of understanding hotel employees' perception on work-life balance issues. International Journal of Hospitality Management, 28(2), 195-203.

https://doi.org/10.1016/j.ijhm.2008.07.001

Yang, G., Tang, W., \& Zhao, R. (2017). An uncertain workforce planning problem with job satisfaction. International Journal of Macbine Learning and Cybernetics, 8(5), 1681-1693. https://doi.org/10.1007/s13042-016-0539-6

Yee, R.W., Yeung, A.C., \& Cheng, T.E. (2008). The impact of employee satisfaction on quality and profitability in high-contact service industries. Journal of operations management, 26(5), 651-668.

https://doi.org/10.1016/j.jom.2008.01.001

Journal of Industrial Engineering and Management, 2020 (www.jiem.org)

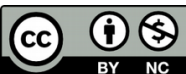

Article's contents are provided on an Attribution-Non Commercial 4.0 Creative commons International License. Readers are allowed to copy, distribute and communicate article's contents, provided the author's and Journal of Industrial Engineering and Management's names are included. It must not be used for commercial purposes. To see the complete license contents, please visit https://creativecommons.org/licenses/by-nc/4.0/. 